\title{
Stochastic semi-continuous simulation for extreme flood estimation in catchments with combined rainfall-snowmelt flood regimes
}

\author{
D. Lawrence ${ }^{1}$, E. Paquet ${ }^{2}$, J. Gailhard ${ }^{2}$, and A. K. Fleig ${ }^{1}$ \\ ${ }^{1}$ Norwegian Water Resources and Energy Directorate (NVE), Oslo, Norway \\ ${ }^{2}$ Electricité de France (EDF-DTG), Grenoble, France \\ Correspondence to: D. Lawrence (dela@nve.no)
}

Received: 28 September 2013 - Published in Nat. Hazards Earth Syst. Sci. Discuss.: 26 November 2013

Revised: 11 April 2014 - Accepted: 11 April 2014 - Published: 23 May 2014

\begin{abstract}
Simulation methods for extreme flood estimation represent an important complement to statistical flood frequency analysis because a spectrum of catchment conditions potentially leading to extreme flows can be assessed. In this paper, stochastic, semi-continuous simulation is used to estimate extreme floods in three catchments located in Norway, all of which are characterised by flood regimes in which snowmelt often has a significant role. The simulations are based on SCHADEX, which couples a precipitation probabilistic model with a hydrological simulation such that an exhaustive set of catchment conditions and responses is simulated. The precipitation probabilistic model is conditioned by regional weather patterns, and a bottom-up classification procedure was used to define a set of weather patterns producing extreme precipitation in Norway. SCHADEX estimates for the 1000-year (Q1000) discharge are compared with those of several standard methods, including eventbased and long-term simulations which use a single extreme precipitation sequence as input to a hydrological model, statistical flood frequency analysis based on the annual maximum series, and the GRADEX method. The comparison suggests that the combination of a precipitation probabilistic model with a long-term simulation of catchment conditions, including snowmelt, produces estimates for given return periods which are more in line with those based on statistical flood frequency analysis, as compared with the standard simulation methods, in two of the catchments. In the third case, the SCHADEX method gives higher estimates than statistical flood frequency analysis and further suggests that the seasonality of the most likely Q1000 events differs from that of the annual maximum flows. The semi-continuous stochastic simulation method highlights the importance of
\end{abstract}

considering the joint probability of extreme precipitation, snowmelt rates and catchment saturation states when assigning return periods to floods estimated by precipitationrunoff methods. The SCHADEX methodology, as applied here, is dependent on observed discharge data for calibration of a hydrological model, and further study to extend its application to ungauged catchments would significantly enhance its versatility.

\section{Introduction}

Precipitation-runoff methods have a long history of application in design flood analyses and represent an important complement to statistical methods, particularly for estimating floods with long return periods. Although event-based methods continue to dominate design flood analysis in practice in many countries, long-term simulation methods are now also feasible due both to increased computational capacity and to advances in the methodologies for generating rainfall input to the simulation (e.g. see discussions in Boughton and Droop, 2003 and Pathiraja et al., 2012). In particular, the introduction and further development of continuous simulation methods for generating a synthetic time series of long duration which can then also be analysed using statistical flood frequency analysis (e.g. Cameron et al., 1999; Blazkova and Beven, 2004) have highlighted the added benefits of such an approach.

Some of the newer simulation approaches are not, strictly speaking, continuous simulations. Rather than generating a full, continuous long-term discharge time series, they instead use single or multiple precipitation events which are 
superimposed on a hydrological simulation based on a historical period. The SCHADEX "semi-continuous" simulation method (Paquet et al., 2006, 2013) is such an approach and represents an efficient strategy for focusing on flood generating events within a simulation framework. In addition, design flood analyses for dam safety in Finland (see Veijalainen and Vehviläinen, 2008, for a brief summary) and Sweden (see Bergström, et al., 1992, 2008) also employ hydrological simulations run over a 10 - to 40 -year historical period coupled with a hypothetical design precipitation sequence, such that a range of potential catchment responses to extreme precipitation are sampled. In this work, we therefore make a distinction between (1) event-based methods which model the catchment response to a selected input precipitation sequence and generally assume a set of pre-event conditions for the catchment; and (2) long-term simulation methods which couple a hydrological simulation for characterising varying catchment conditions with an input precipitation, based either on a single design precipitation sequence or on a probabilistic methodology for generating multiple precipitation events. This is in contrast to the distinction that is typically used for describing precipitation-runoff methods for design flood analysis, i.e. event-based vs. continuous simulation methods (e.g. Grimaldi et al., 2013). A further distinction could be made between methods which use a fixed design precipitation sequence and those which consider a range of possible rainfall events. Flood simulations using a single design hyetograph assume a fixed relationship between the return period of rainfall event and that of the simulated flood event, which is itself problematic (Rahman et al., 2002; Kuczera et al., 2006). In such simulations, the temporal sequence of the rainfall is also specified in terms of the shape of the hyetograph and the duration of the event. Alternative methods which consider catchment response to a range of precipitation events, either as an event-based model or in a long-term simulation mode, have clear advantages over the classical use of a design hyetograph with respect to assigning return periods to the simulated events (Cameron et al., 1999; Paquet et al., 2013).

From the perspective of the practitioner, it is important that extreme flood analysis methods, regardless of the approach used, produce consistent estimates which are comparable between applications in differing regions and, simultaneously, that the methods are not severely restricted by their data requirements. In the Nordic countries snowmelt is an important factor contributing to flood generation in most areas, and the selected modelling methodology must include a robust strategy for accounting for this contribution to peak runoff. This can be a particular challenge for event-based methods, especially in areas and for seasons for which snow accumulation and melting are quite transient (e.g. early autumn in mountainous areas or mid-winter in some coastal areas) or spatially varying (e.g. in catchments with pronounced topography). Long-term simulation methods are, in principle, more suitable for estimating the return period of combined snowmelt/rainfall events as variability in the snowmelt contribution to runoff, as well as in the saturation status of the catchment, are to a certain degree simulated by the hydrological model. Although recent publications (e.g. Camici et al., 2011; Pathiraja et al. 2012) have highlighted the advantages of long-term simulation with respect to accounting for varying antecedent soil moisture conditions, little published work has evaluated its use for extreme flood estimation in areas where snowmelt can have a significant role throughout much of the year.

In this work, we consider extreme flood estimation in three catchments of moderate size $\left(207-436 \mathrm{~km}^{2}\right)$, all located in Norway. The three catchments are susceptible to extreme flows caused by a combination of heavy rainfall and snowmelt, although there are differences in the seasonality of peak flows and in the relative contribution of snowmelt to annual runoff. The focus here is on the application of SCHADEX semi-continuous simulation and particularly considers its suitability for analysing extreme floods caused by a combination of extreme precipitation and snowmelt. The results of the SCHADEX application are compared with other methods for design flood analysis in the Nordic region, including (1) a simple, event-based, method for estimating peak discharge in response to a predefined extreme precipitation sequence, which represents standard practice for design flood analysis in Norway; and (2) a long-term simulation using a calibrated hydrological model together with an extreme precipitation sequence that is iterated through a simulation period, which is similar to the simulation methods used for design flood analyses in Finland and Sweden. A comparison of all three precipitation-runoff methods is also made with statistical flood frequency analysis based on observed discharge data and with the GRADEX method (Guillot, 1993) for flood estimation, which is widely applied outside of the Nordic region.

\section{Study catchments}

Three catchments were used for the SCHADEX applications and the comparisons with other methods: (1) Atnasjø $\left(463 \mathrm{~km}^{2}\right)$, located in the central mountainous region of southern Norway, (2) Engeren $\left(395 \mathrm{~km}^{2}\right)$, located in the inland region of eastern Norway, and (3) Krinsvatn $\left(207 \mathrm{~km}^{2}\right)$, located along the western coast of mid-Norway (Fig. 1). These particular catchments were selected as they all have (a) long daily discharge records, i.e. approximately 100 years of record; (b) available hourly discharge values for up to twenty-year periods which can be used for developing estimates of peak to volume ratios for the SCHADEX method; (c) extreme flood regimes characterised by a combination of heavy rainfall and snowmelt; and (d) relatively pristine catchments largely unaffected by river regulation.

The characteristics of the three catchments are summarised in Table 1. Atnasjø is characterised by a 
Table 1. Catchment characteristics.

\begin{tabular}{|c|c|c|c|}
\hline & Atnasjø & Engeren & Krinsvatn \\
\hline \multicolumn{4}{|l|}{ Physiography } \\
\hline Catchment area $\left(\mathrm{km}^{2}\right)$ & 463 & 395 & 207 \\
\hline Median elevation (m a.s.l.) & 1204 & 837 & 349 \\
\hline Maximum elevation (m a.s.1.) & 2169 & 1207 & 627 \\
\hline Minimum elevation (m a.s.l.) & 701 & 472 & 87 \\
\hline \multicolumn{4}{|l|}{ Climate } \\
\hline Mean annual precipitation $\left(\mathrm{mm} \mathrm{yr}^{-1}\right)$ & 852 & 969 & 2473 \\
\hline Mean January temperature $\left({ }^{\circ} \mathrm{C}\right)$ & -11.8 & -10.4 & -3.0 \\
\hline Mean July temperature $\left({ }^{\circ} \mathrm{C}\right)$ & +8.7 & +11.4 & +11.6 \\
\hline \multicolumn{4}{|l|}{ Land cover } \\
\hline Forest $(\%)$ & 21 & 49 & 21 \\
\hline Lake $(\%)$ & 2 & 4 & 8 \\
\hline Marsh and bog $(\%)$ & 3 & 16 & 10 \\
\hline Sparse vegetation over treeline $(\%)$ & 70 & 30 & 61 \\
\hline Other (e.g. meadows, populated areas) (\%) & 4 & 0 & 1 \\
\hline Effective lake percentage (\%) & 1.1 & 2.7 & 1.1 \\
\hline \multicolumn{4}{|l|}{ Hydrologic regime } \\
\hline Mean annual runoff $\left(\mathrm{mm} \mathrm{yr}^{-1}\right)$ & 655 & 588 & 1917 \\
\hline Mean annual maximum daily flow $\left(\mathrm{m}^{3} \mathrm{~s}^{-1}\right)$ & 71 & 53 & 131 \\
\hline Maximum observed daily discharge $\left(\mathrm{m}^{3} \mathrm{~s}^{-1}\right)$ & 187 & 136 & 336 \\
\hline Season for annual maximum flows & $\begin{array}{l}\text { Mid-May- } \\
\text { early July }\end{array}$ & $\begin{array}{r}\text { May- } \\
\text { mid-June }\end{array}$ & $\begin{array}{r}\text { September- } \\
\text { February }\end{array}$ \\
\hline
\end{tabular}

snowmelt-dominated flood regime, with the highest annual flows usually occurring in late May and June. High flows can, however, also occur in the late summer and early autumn in response to heavy precipitation, and sometimes in conjunction with early autumn snow accumulation and melting. The mean annual flood for the period 1916-2012 is $71 \mathrm{~m}^{3} \mathrm{~s}^{-1}$, and the highest observed daily averaged $Q$ is $187 \mathrm{~m}^{3} \mathrm{~s}^{-1}$ (1 June 1995). The catchment elevation ranges from 701 to $2169 \mathrm{~m}$ a.s.l., and the estimated average January and July temperatures at the catchment median elevation (1204 m a.s.1.) are $-11.8^{\circ} \mathrm{C}$ and $+8.7^{\circ} \mathrm{C}$, respectively. The average annual runoff is estimated as $655 \mathrm{~mm}$ year $^{-1}$ in response to an estimated precipitation of $852 \mathrm{~mm}$ year $^{-1}$ The flood regime at Engeren shares many similarities with Atnasjø in that most of the highest annual flows occur during the seasonal snowmelt period, which in Engeren is from early May to mid-June. The slightly earlier snowmelt reflects the lower catchment elevation, in that the catchment topography ranges from 472 to $1207 \mathrm{~m}$ a.s.l. The estimated average January and July temperatures at the catchment median elevation ( $837 \mathrm{~m}$ a.s.1.) are $-10.4{ }^{\circ} \mathrm{C}$ and $+11.4{ }^{\circ} \mathrm{C}$, respectively. The mean annual flood for the period 1911-2012 at Engeren is $53 \mathrm{~m}^{3} \mathrm{~s}^{-1}$, and the highest observed daily averaged $Q$ also occurred on 1 June 1995, as at Atnasjø, and is $136 \mathrm{~m}^{3} \mathrm{~s}^{-1}$. The catchment has a similar water balance to that of Atnasjø, although evaporation is higher in summer months, resulting in an estimated annual runoff of $588 \mathrm{~mm} \mathrm{year}^{-1}$ in response to an estimated precipitation of $969 \mathrm{~mm}$ year $^{-1}$. Krinsvatn, in contrast to the other two catchments, has a much warmer and wetter coastal location, with estimated average January and July temperatures at the catchment median elevation ( $349 \mathrm{~m}$ a.s.1.) of $-1.5^{\circ} \mathrm{C}$ and $+13.2^{\circ} \mathrm{C}$, respectively. Catchment elevation ranges from 87 to $627 \mathrm{~m}$ a.s.1. The flood regime is dominated by peak events in middle to late autumn, throughout the winter and in early spring, although high flows can occur throughout the year. Some of the largest events have occurred during wet periods during the autumn and winter in which extreme rainfall occurs simultaneously with snowmelt induced by warm temperatures. The mean annual flood for the period 19152012 is $131 \mathrm{~m}^{3} \mathrm{~s}^{-1}$, and the highest observed averaged daily $Q$ is $336 \mathrm{~m}^{3} \mathrm{~s}^{-1}$ (31 January 2006). The much higher discharge values relative to Atnasjø and Engeren (despite Krinsvatn's smaller catchment area) reflect differences in the annual water budget. Krinsvatn has an estimated annual runoff of $1917 \mathrm{~mm} \mathrm{year}^{-1}$ in response to an estimated annual precipitation of $2437 \mathrm{~mm}$ year $^{-1}$.

All three catchments are dominated by coniferous forest cover in the lower reaches and by sparsely vegetated surfaces over the treeline in the higher reaches. There are differences in the percentage of the land surface covered by lakes and marshes (17\% for Krinsvatn and $20 \%$ for Engeren, as opposed to $4 \%$ for Atnasjø), with both Krinsvatn and Engeren having more abundant surface water storage. The effective lake percentage, $A_{\text {se }}$, which is defined as

$A_{\mathrm{se}}=100 * \Sigma\left(\left(A_{\mathrm{i}} * a_{\mathrm{i}}\right) / A^{2}\right)$, 


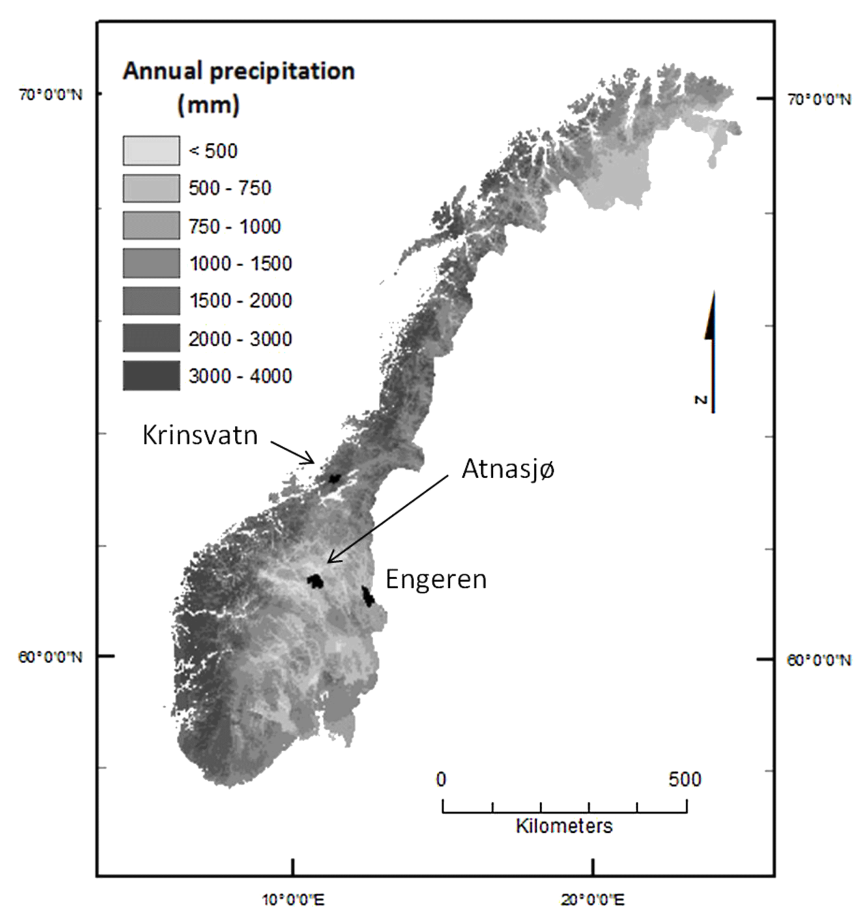

Figure 1. Catchment locations and spatial pattern of average annual rainfall (1961-1990) in Norway.

where $a_{\mathrm{i}}$ is the surface area of an individual water body, $A_{\mathrm{i}}$ is the contributing area to that water body, and $A$ is the total catchment area used to take account of the location of surface water relative to the catchment outlet as a measure of its capacity to attenuate peak discharges. This has a value of between 1 and $3 \%$ in the three catchments.

\section{The SCHADEX method}

SCHADEX, developed and widely applied in France (Paquet et al., 2006, 2013), is a probabilistic method for extreme flood estimation. The method uses a "semi-continuous" simulation in which observed "centred" rainfall events in the climatological record are replaced by synthetic events. Centred rainfall events are identified based on a combined analysis of the precipitation and discharge records, such that precipitation events producing an over-threshold discharge are identified. In common practice, the selected centred rainfall events are 3-day events comprised of a central (daily) rainfall value and the two adjacent rainfall values, and these three days are replaced with synthetic values. The value for the central rainfall is randomly drawn from values between $1 \mathrm{~mm}$ and an extreme quantile, whereas the adjacent values are described by their ratio relative to the central value and values are accordingly drawn between 0 and 1 . The synthetic values are used in a hydrological simulation based on the observed climatological record up to the 3-day event which is to be replaced and then using the synthetic values for those three days. This re- placement process is repeated hundreds of times for each actual centred rainfall event, generally corresponding to about 70-80 different days per year. In the full simulation process, a total of $\sim 2 \times 10^{6}$ events is generated, such that a probability distribution of discharge resulting from rainfall under a range of catchment conditions, including varying rates of snowmelt, can be constructed. The resulting distribution of flow events can then be analysed to assess flood magnitudes corresponding to particular return periods, and the distribution of catchment saturation conditions, snowmelt rates and rainfall intensities associated with the events can also be summarised. Full details of the underlying mathematical structure of the SCHADEX approach and the various steps involved in an application of SCHADEX can be found in Paquet et al. (2013).

\subsection{Development and application of a weather-type classification}

The probabilistic description of the central rainfall values used in SCHADEX is based on the Multi-Exponential Weather Patterns (MEWP) distribution introduced by Garavaglia et al. (2010). In order to implement this approach for catchments in Norway, a set of regional atmospheric circulation patterns useful for distinguishing distributions of extreme rainfall intensities in the region is required. Regional weather types (WT) were therefore defined following the procedure proposed by Gailhard (2010). Three different methods were considered, all of which have in common the use of both large-scale synoptic data and local precipitation data. Due to the use of station-based precipitation data in the procedure, the three methods can be considered to be bottom-up approaches to weather type classification. The application and testing of the three methods for the Norwegian data sets are described in detail in Fleig (2011) and only the main points are reviewed here.

Atmospheric pressure data were obtained from the NCEP/NCAR reanalysis project (Kalnay et al., 1996) and include geopotential height data centred over Norway $(0$ $\left.20^{\circ} \mathrm{E}, 55-70^{\circ} \mathrm{N}\right)$ for the $1000 \mathrm{hPa}$ level (Z1000) and the $700 \mathrm{hPa}$ level (Z700) at UTC at a spatial resolution of $2.5^{\circ} \times 2.5^{\circ}$. Precipitation data for the period 1970-2008 for 175 stations distributed across Norway were extracted from the "European Climate Assessment \& Dataset" (ECA\&D, 2011) database. These stations and the time period were selected out of the 368 available stations for the region, such that no station had more than 50 days with missing data. The locations of the precipitation stations and the grid of geopotential heights are presented in Fig. 2.

The first method (Method 1) is described in detail in Garavaglia et al. (2010) and in Brigode et al. (2013) and begins with a classification of the rainy days, grouped according to their "ground fingerprint", i.e. the shape of the rain field in the domain of interest. The average synoptic pattern associated with each rain-field class is then identified. The second 


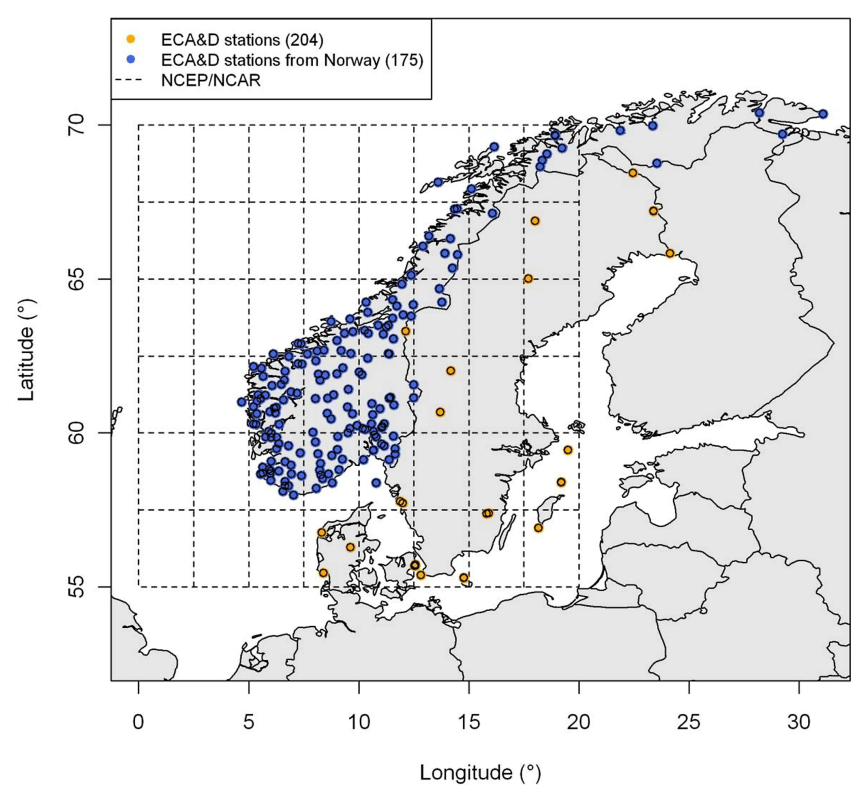

Figure 2. Precipitation stations and grid of geopotential heights used to build the WT classifications for Norway.

method (Method 2) is inspired by Plaut et al. (2010) and begins by analysing the synoptic situations associated with intense precipitations at each station. This is accomplished by calculating the average synoptic situation for the 30 highest observed precipitations. The average active synoptic situations can then be classified, which results in a grouping of the weather stations. Finally, for each group of precipitation stations, an average synoptic situation corresponding to intense precipitation is computed based on all the synoptic situations of the class $\left(30 \times n_{i}\right.$, where $n_{i}$ is the number of stations in group $i$ ). The third method (Boé and Terray, 2008), here referred to as Method 3, uses a direct classification of all days, using both the "ground fingerprint" and the synoptic situation as identified in the pressure field, following variance normalisation. All three methods also included an additional weather type in the classification scheme to account for days without rain, so that all days within a continuous daily record could be assigned a weather type.

The three methods use the same variables for describing the synoptic situation. As demonstrated in Brigode et al. (2013), it is useful to consider two levels for the pressure field description (the 1000 and $700 \mathrm{hPa}$ geopotentials), and two points in time for these values $(0 \mathrm{~h}$ on the day of interest and $0 \mathrm{~h}$ on the following day). These four variables have also been recommended by Obled et al. (2002) based on their evaluation of the performance of different combinations of these four fields for probabilistic precipitation estimation. All three methods have taken these four variables into use.

Two scores were used to assess the discriminating power of the classifications: the within-type variability and the Cramer score (Anderson, 1962). The Cramer score evaluates

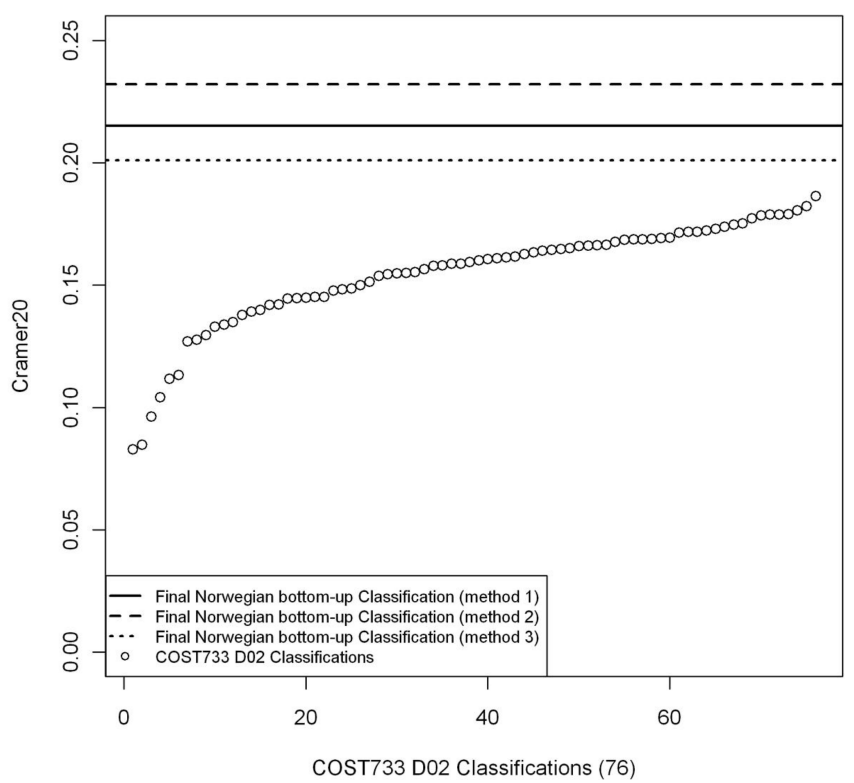

Figure 3. Distribution of Cramer20 scores for the 76 COST733 classifications, as compared with the scores for the three classifications described in Sect. 3.1.

the discriminating power of a WT classification in terms of the occurrence of rain vs. no rain, as applied in Bárdossy et al. (1995). To place the focus on performance with respect to heavy precipitation, as opposed to all values of precipitation, the Cramer coefficient can be estimated on days with a precipitation greater than a given threshold. In the work presented here a $20 \mathrm{~mm}$ threshold was used, and this "heavy rain Cramer" coefficient is referred to here as the "Cramer 20 coefficient". It is computed for each station and is then averaged on the whole domain to develop a score which can be used to compare the classification methods.

The WT classifications developed using the three different methods were all found to perform well in comparison with the 76 classifications of COST733 (Tveito et al., 2011), as illustrated in Fig. 3. Regionally, the three classifications were found to have a higher discriminating power and lower within-type variability along the western coast of Norway as compared with inland locations. In addition, the area in which the performance was poorest was in the central mountainous region of southern Norway (e.g. in the area around Atnasjø, Fig. 1). In this region, extreme precipitation events can be caused by a number of different atmospheric circulation conditions, resulting in air flow from a variety of directions. Figure 4 shows the dominant wind direction on the 30 days with highest precipitation at each station, as identified with the second method. The size of the arrow indicates how strongly this wind direction dominates within those 30 days. The pattern illustrated here indicates that in southern Norway, east of the topographic water divide, extreme precipitation is typically caused by a south to north air flow, whereas air coming from the west is responsible for most 


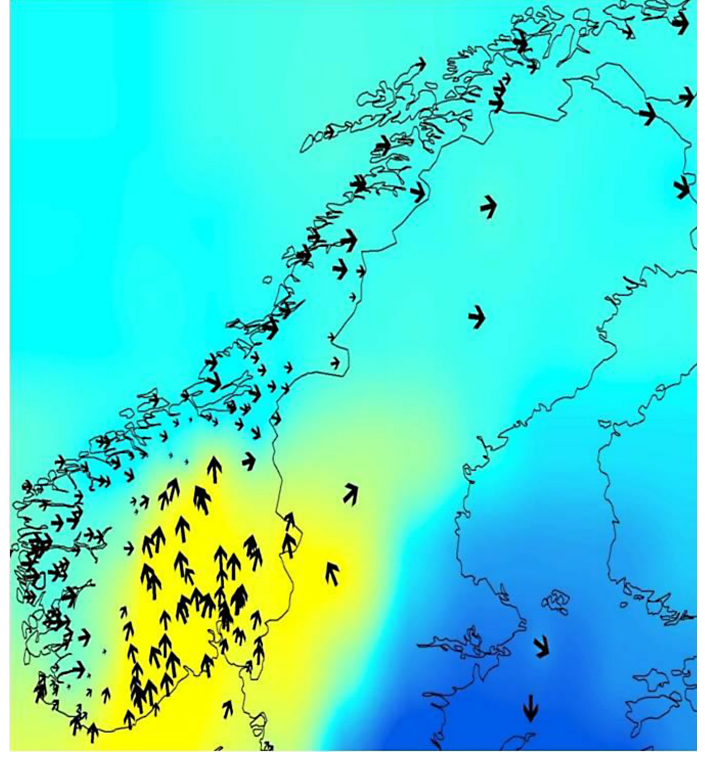

Figure 4. Dominant wind direction on the 30 days with the highest precipitation values at each station.

of the extreme precipitation events in western and northern Norway. In mid-Norway, the dominance of this wind direction is limited and air coming from other directions can also induce extreme precipitation.

Three WT classifications produced by each of the three methods were used to develop preliminary rainfall probabilistic models for the SCHADEX applications for the Atnasjø and Krinsvatn catchments. These initial trials led to the choice of Method 1 for the weather type classification, although it performs slightly more poorly than Method 2 (Fig. 3). In addition, during this process it was recognised that some of the seven WTs could be combined into four weather patterns (WP), thus improving the robustness of the fitted distributions as more events were available for each WP. The assessment of this robustness could have been based on statistical scores (as detailed in Garavaglia et al. (2011)), but in this case the choice has been made using expert judgment. This simplification of the classification was found to have a negligible effect on the final SCHADEX estimates and was, thus, retained. The resulting four WPs used in the SCHADEX applications for Norway, including the eight underlying WTs on which they are based, are illustrated in Fig. 5.

\subsection{Defining MEWP distributions for centred rainfall}

For the application of SCHADEX to a given catchment, two to four relevant seasons are defined within the year, and the seasonal record for the areal precipitation (constructed from local station-based precipitation data) is then split into subsamples corresponding to each WP. An exponential law is fitted to the high quantiles of the central rainfalls correspond-

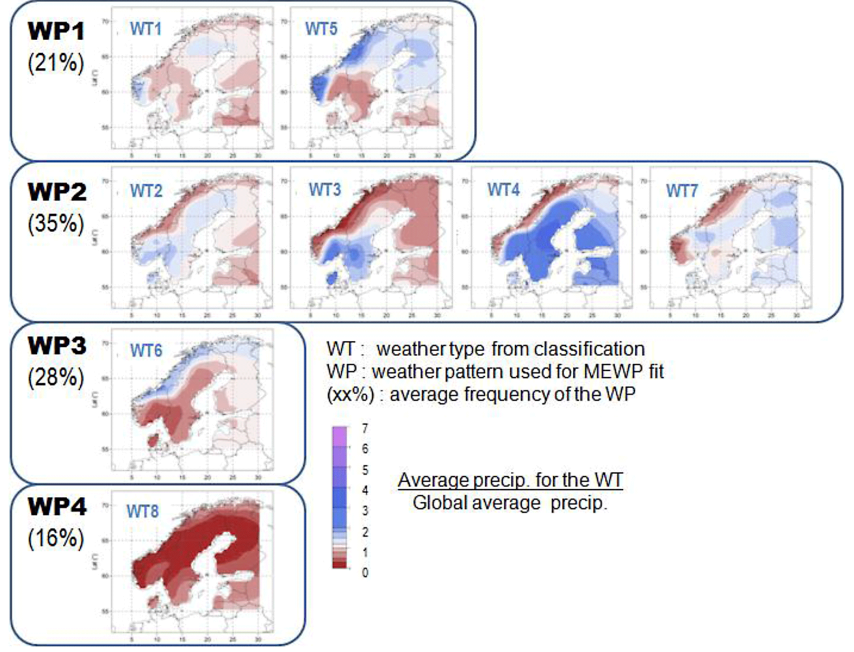

Figure 5. Three weather pattern groups representing seven weather types leading to extreme precipitation and one weather type (WT8/WP4) representing dry days.

ing to each WP sub-sample (generally over the $70 \%$ empirical quantile). For a given season, the MEWP distribution is composed of the marginal distribution associated with each WP, weighted by the relative frequency of occurrence of each WP for the considered season. In practise, alternative groupings of months into seasons are often considered before the final set of seasonally fitted distributions is selected. Further details regarding the use of the MEWP for characterising extreme rainfall can be found in Garavaglia et al. (2010).

The application of MEWP is illustrated in Figs. 6 and 7 for the Atnasjø catchment. In Fig. 6, the plots on the right-hand side show the observed distributions of the Atnasjø areal precipitation for a given season (22 May-21 October) corresponding to each WP and the exponential laws fitted to the values over a threshold (in this case $\sim 10 \mathrm{~mm} \mathrm{day}^{-1}$ ). The plot on the left-hand side shows the seasonal MEWP distribution built by combining the marginal exponential laws. This WP sampling shows clearly that, for this case, the WP2 represents the highest precipitation risk, with the observed maximum almost twice as large as the maximum values for the other WPs. Figure 7 illustrates the four seasonal MEWP distributions for Atnasjø and the corresponding observations. The "season-at-risk" is here the third season (22 May-21 October), including the June-July period corresponding to peak rates of seasonal snowmelt. By using sub-samples based on weather patterns, corresponding to grouping events which have a similar meteorological genesis, more homogeneous sub-samples are established for the statistical analysis than would be the case if weather pattern sub-sampling were not used. Thus, one expects that the "i.i.d." hypothesis (i.e. that events are independent and identically distributed) underlying the extreme value theory is more closely met by such an approach. The benefits of using such an approach in practise 

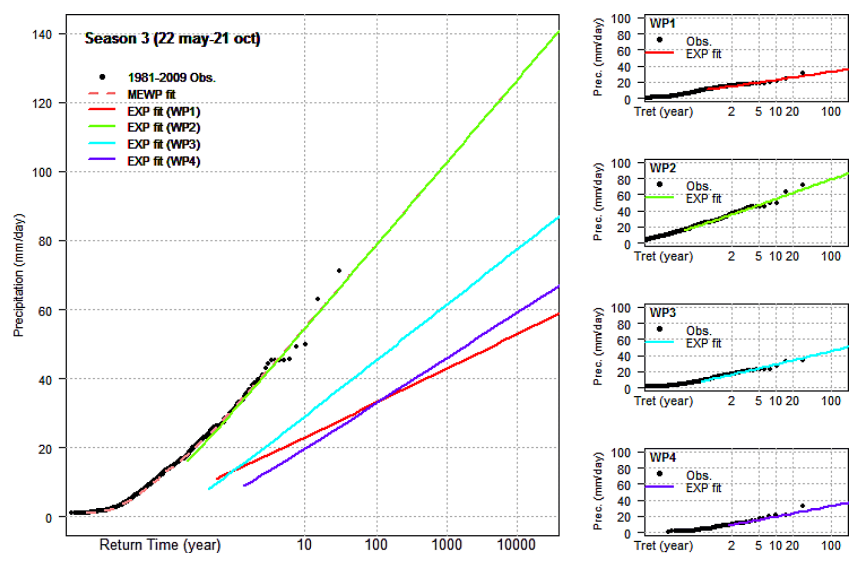

Figure 6. Example of WP-based fits for the June-October season at Atnasjø (right) with the resulting seasonal MEWP distribution (left).

with respect to the reliability and robustness of the extreme values analyses are presented in Garavaglia et al. (2011).

Ancillary probabilistic models complement the MEWP distribution to account for adjacent rainfall (i.e. the day before and the day after the central rainfall) and for assessing the probability of the precipitation sequence which occurs during the few days preceding a centred event (i.e. the antecedent rainfall prior to the 3-day synthetic event). For the adjacent rainfall values (i.e. ratios relative to the central value), a contingency table is used to assign probabilities to the values drawn from the uniform distribution between 0 and 1 . The boundaries between the classes used are chosen such that the classification is focused on the heaviest precipitation events. The probability of the precipitation preceding the 3-day event is assessed based on the conditional probability of the simulated event, given the antecedent precipitation, specified as a stochastic variable described by the sum of two exponential distributions (Djerboua et al., 2004). The complete probabilistic scheme is described in detail in Paquet et al. (2013).

\subsection{Hydrological modelling and analysis for the SCHADEX applications}

For the SCHADEX applications, the MORDOR hydrological model, which is a lumped conceptual precipitation-runoff model also incorporating a sub-model for snow accumulation and melting processes (Garçon, 1996), was used. The MORDOR model was calibrated for the three Norwegian catchments based on a genetic algorithm with an objective function designed to maximise both the Nash-Sutcliffe (N-S) efficiency criterion and the fit between the observed and modelled empirical CDF of flow values. Calibration was based on a selection of 20 years between the period 1973-2010 for the three catchments, and the resulting $\mathrm{N}-\mathrm{S}$ validation values were $0.85,0.76$ and 0.83 for Atnasjø, Engeren and Krinsvatn,
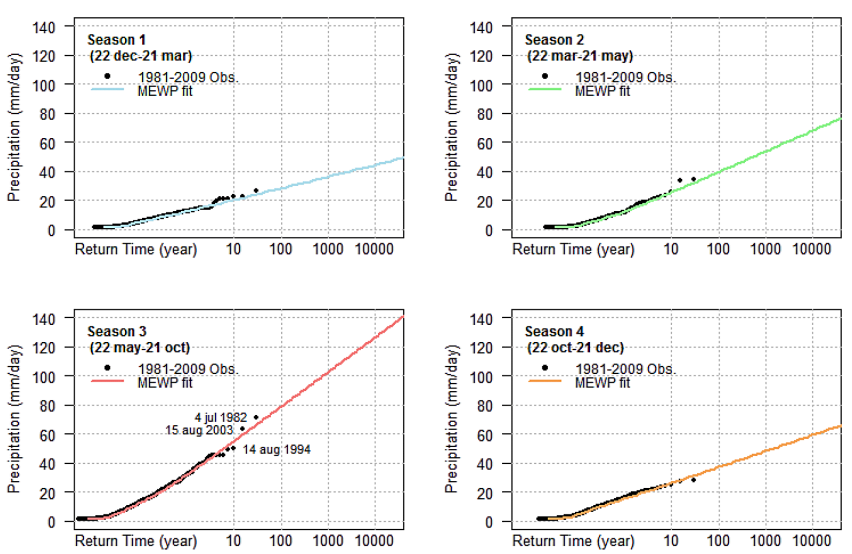

Figure 7. Seasonal MEWP distributions for Atnasjø.

respectively. Comparisons between simulated and observed daily inter-annual mean discharge are illustrated in Fig. 8 and indicate a good overall fit between modelled and simulated values. The differences in the catchment flow regimes are also highlighted in this figure, as are the differences between the general period of peak flows and the distribution of the annual maximum values by month. In particular, at Krinsvatn, there is a notable difference between the period of highest daily average values (i.e. April to May), which corresponds to a period of seasonal snowmelt, and the monthly distribution of the annual maximum series, which indicates that high flows can occur throughout the year.

Hourly discharge data were used to estimate peak-tovolume ratios (for converting simulated daily discharge values to instantaneous peak values). The average centred peakto-volume ratios are 1.04, 1.01 and 1.25 for Atnasjø (19872011), Engeren (1987-2011) and Krinsvatn (1970-2011), respectively, based on peak-over-threshold selection of hydrographs of major flood events within the hourly discharge record. These values are very similar to those which would be obtained from the regression equations for the ratio of the instantaneous peak flow relative to the average daily flow developed for Norway for different seasons (e.g. Midttømme, et al. (2011), p. 26). This suggests negligible differences between the sub-daily and daily values for peak flows at Atnasjø and Engeren, although at Krinsvatn the instantaneous values are significantly higher. The primary factor leading to the much lower values at Atnasjø and Engeren is the presence of a snow cover during most periods of high flow, which can delay some of the incoming rainfall due to the time lag associated with percolation through the snow cover. In addition, Krinsvatn is a smaller catchment (Table 1). At Krinsvatn, most of the peak flows occur outside of the period in which a significant snow cover is present, leading to a much higher value. 

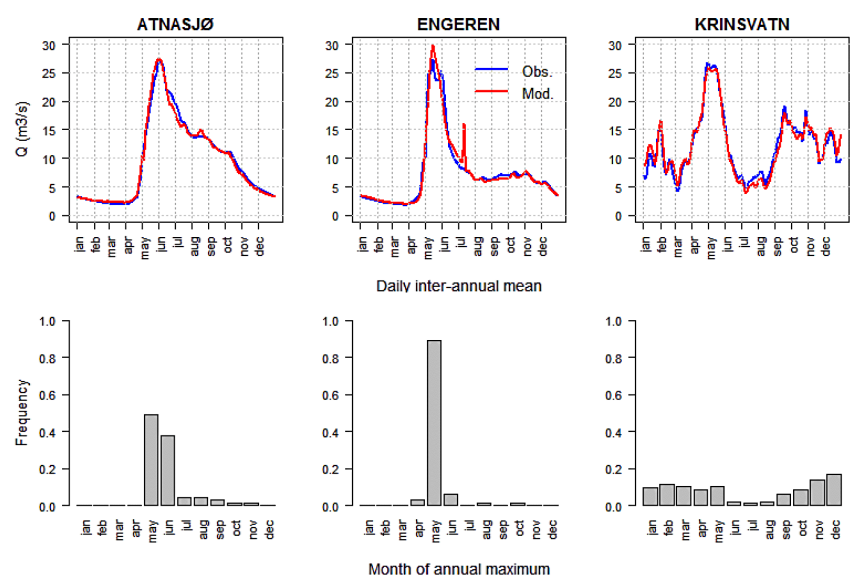

Figure 8. Daily inter-annual mean for both observed and modelled values and relative frequency of annual maxima by month.

\subsection{SCHADEX stochastic simulations}

The SCHADEX simulations were run on a daily time step, corresponding to that of the calibrated hydrological model. For the three catchments, the simulation periods were approximately 40 years in length, thus encompassing a wide range of hydrological situations, including the conditions producing the highest observed discharges. The simulation periods were also shorter than the entire period of the discharge record, as these were constrained by the availability of station-based precipitation data for creating an areal rainfall for use in defining the centred rainfall events and for running the hydrological model. The simulation periods were 19742010, 1970-2008, and 1971-2010, for Atnasjø, Engeren and Krinsvatn, respectively. The stochastic simulations were run using the steps delineated in Paquet et al. (2013), and they produced $\sim 2 \times 10^{6}$ flow events in each catchment. A comparison of the distribution of these events with the annual maxima for the entire period of record and with the observed discharges associated with the centred rainfall events $\left(Q J_{\mathrm{c}}\right)$ is illustrated in Fig. 9 for the three catchments. The results indicate good to very good correspondence between the simulated SCHADEX distribution and the observed values. In some cases, the return periods corresponding to the highest observed events seem to be underestimated at Atnasjø and Krinsvatn. It must be kept in mind, however, that the empirical return period associated with the highest observed flows is very uncertain due to the length of the period of observation. The SCHADEX distributions, as an alternative, indicate return periods of 270 and 407 years for the highest events at Atnasjø (1 June 1995) and Krinsvatn (31 January 2006), respectively. The SCHADEX estimation for Engeren gives a return period of 44 years for the historical flood of June 1995.
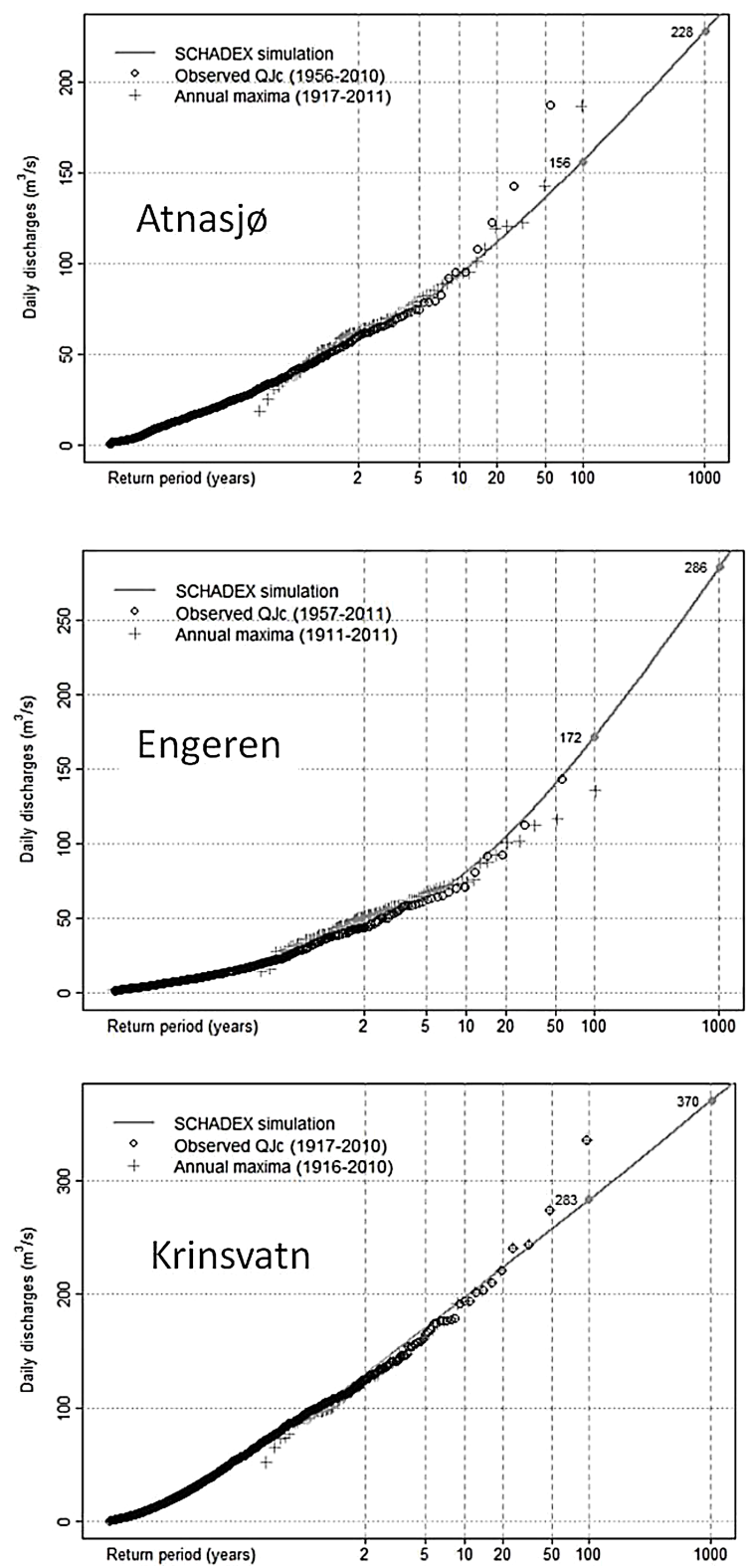

Figure 9. Distribution of daily discharge values based on SHADEX, as compared with the observed annual maxima and the observed discharges associated with centred rainfall events $\left(Q J_{\mathrm{c}}\right)$.

\section{Methods applied for comparisons with SCHADEX results}

A meaningful assessment of the value of the stochastic semicontinuous simulation approach for practical applications can only be made by comparison with standard methods. We have therefore also applied two other precipitation-runoff methods often used in conjunction with dam safety analysis in the Nordic region: (1) an event-based model (hereafter referred to as PQRUT); and (2) a long-term simulation using a calibrated HBV hydrological model coupled with an extreme 
precipitation sequence (hereafter referred to as HBV-Design Flood). In addition, the GRADEX method has been implemented for all three catchments, as this is a method which is widely applied outside of the Nordic region. Although GRADEX is not a simulation method, it can be considered to be a type of precipitation-runoff method, as it uses an extreme value distribution based on precipitation to assess likely increases in runoff as a function of return period.

\subsection{Event-based modelling with PQRUT}

Extreme flood estimation for dam safety using precipitationrunoff methods in Norway often employs a simple threeparameter catchment model, PQRUT, driven by a predefined precipitation sequence. The sequence is constructed from estimates of rainfall intensity for durations corresponding to the concentration time of the system of interest. These estimates are derived following the NERC (1975) method, as further developed for use in Norway (Førland, 1992). The method uses empirical growth curves to estimate intensity for various durations based on the so-called "M5" value (i.e. the $24 \mathrm{~h}$ rainfall with a 5-year return period), and in standard practice this estimate is based on a Gumbel extreme value distribution. To simulate combined rainfall/snowmelt events, an additional contribution is added to the sequence, and this is derived from a simple temperature-based estimate of the maximum melting rate for a given surface cover type. In more complex applications, a simple snowmelt model can be used to take account of differences in snow depth and depletion as a function of catchment elevation, but such applications are rare in practice. The combined precipitation/snowmelt sequence is then used as input to the PQRUT catchment response model.

The PQRUT catchment response model is usually run on an hourly time step, reflecting the small size and rapid response of the catchments often under consideration. Catchment response to the rainfall/snowmelt input sequence representing the extreme event is described using a threeparameter lumped "bucket"-type model in which outflow in response to inflow occurs either at a faster or a slower rate, depending on the value of accumulated depth relative to a threshold. As most extreme flood estimates for dam safety analyses in Norway are developed for ungauged catchments, values for the three PQRUT parameters are set based on three catchment physical characteristics (catchment steepness, effective lake percentage, and normal runoff) using empirically derived formulas, although these can also be calibrated if sufficient precipitation and discharge data are available at the required temporal resolution. In most applications, the catchment is assumed to be fully saturated at the onset and throughout the simulated event, although an initial deficit volume can also be set. Further details regarding the method and its application can be found in Midttømme et al. (2011), and a summary of the method is also available in Wilson et al. (2011) in English.

\subsection{Long-term hydrological simulation with HBV-Design Flood}

Design flood estimation in Finland and Sweden is also based on a single design rainfall sequence, and a 14-day sequence with a temporal pattern appropriate to the region of interest is used. This sequence is, however, coupled with a full hydrological simulation using an HBV-type model (Bergström, 1976) for the catchment. The simulation is run for a period of 10-40 years based on observed precipitation and temperature data, and the design rainfall sequence replaces a 14-day period within the historical precipitation series during the hydrological simulation. The design sequence is then moved forward by a day and a new simulation is run. This process is repeated through the entire observed series, such that the catchment response to the design precipitation under the range of soil moisture and snowmelt conditions is sampled. In Sweden, it is also assumed that the snow water equivalent at the commencement of the design precipitation has a 30-year return period. Further details of these methods, which represent a type of long-term simulation, can be found in Bergström et al. $(1992,2008)$ and Veijalainen and Vehviläinen (2008). A significant advantage of this approach over event-based methods is that catchment response to the extreme precipitation sequence under a range of catchment conditions corresponding to differing saturation states and contributions from snowmelt is sampled during the simulation process.

\subsection{Application of PQRUT and HBV-Design Flood to the study catchments}

For the application of PQRUT and HBV-Design Flood (HBV-DF), design precipitation sequences for the 500- and 1000 -year events were constructed from values estimated by the Norwegian Meteorological Institute for durations ranging from 1 to $480 \mathrm{~h}$ (see Førland, 1992 for further details of the method). As an example and for comparison, the estimated seasonal 1, 6, 24, 72, and 336 h (14-day) values for the 1000-year event are 50, 89, 134, 176, and $247 \mathrm{~mm}$ for JuneAugust for Atnasj $\varnothing, 48,89,138,176$, and $250 \mathrm{~mm}$ for JuneAugust for Engeren, and 55, 113, 197, 283, and $451 \mathrm{~mm}$ for October-November for Krinsvatn, respectively. These values were nested to produce 72 and $336 \mathrm{~h}$ design precipitation sequences for use in PQRUT, and the same sequences were also used for the HBV-Design Flood simulations. In addition, for the PQRUT application, a snowmelt contribution of $1.25 \mathrm{~mm} \mathrm{~h}^{-1}\left(30 \mathrm{~mm} \mathrm{~d}^{-1}\right)$ was used for all three catchments. This value represents approximately $70 \%$ of a maximum value of $45 \mathrm{~mm} \mathrm{~d}^{-1}$, estimated based on an air temperature of $10^{\circ} \mathrm{C}$ and a surface cover dominated by forest in the lower reaches and sparse vegetation above the treeline. Note that this is an average contribution for the entire catchment, which in all cases will have differing patterns of snow storage, snow ripening processes and, accordingly, contributions 


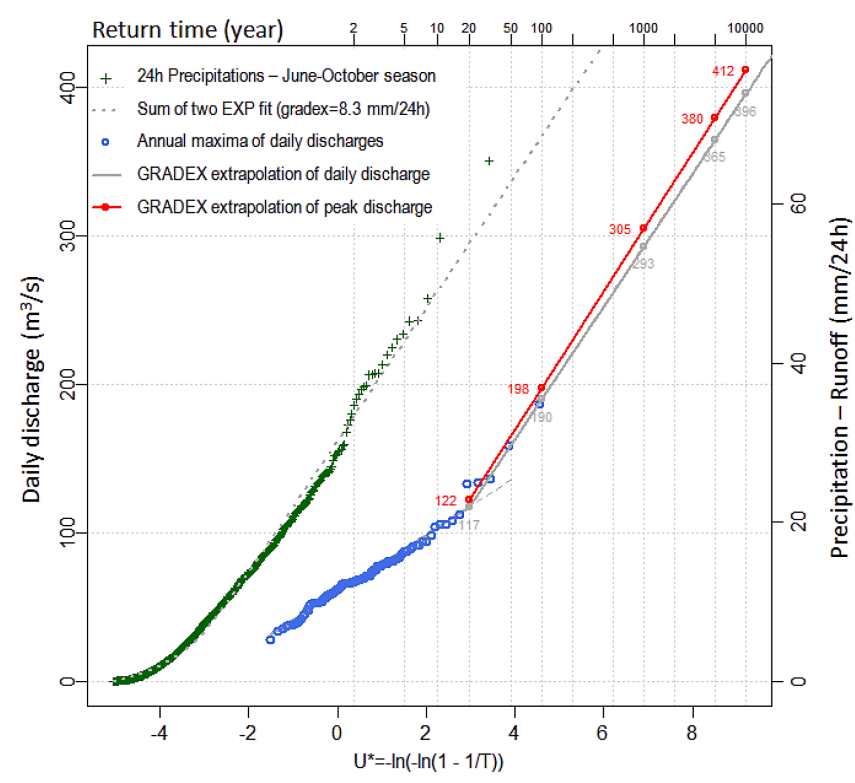

Figure 10. Application of GRADEX to Atnasjø, as described in Sect. 4.4.

to runoff in differing elevation zones within the catchment. In addition, following standard practice, the catchment was assumed to be fully saturated at the onset of the PQRUT simulation. For the HBV-Design flood application, the Nordic version of HBV (Sælthun, 1996) was used, and HBV model parameters were estimated using the calibration procedures described in Lawrence et al. (2009). The HBV model validations produced $\mathrm{N}-\mathrm{S}$ efficiencies of $0.77,0.77$, and 0.78 for Atnasjø, Engeren and Krinsvatn, respectively. The HBV simulations are run on a daily time step, and instantaneous peaks are estimated based on empirical formulas which take account of flood season, catchment area and effective lake percentage (Midttømme et al., 2011). Applying these formulae, the ratio of instantaneous peak to daily averaged discharge is 1.14, 1.07, and 1.37 for Atnasjø, Engeren and Krinsvatn, respectively. Note that the peak values based on these formulae give slightly higher values than those based on the actual analysis of sub-daily data (Sect. 3.3).

\subsection{The GRADEX method and its application}

The GRADEX method has been used in France to estimate design floods for dam safety for more than 30 years. It is applied here as described in Duband and Garros-Berthet (1994), and the application is illustrated in Fig. 10 for Atnasjø. A sum of two exponentials (STE) distribution is first fitted to the daily precipitation of the season with the highest flood risk of the catchment. Daily values are adjusted to account for the rain-snow limit, based on the daily mean air temperature values and the hypsometry of the catchment. The GRADEX parameter is the slope of the asymptotic exponential law (the grey dotted line in Fig. 10) in a Gumbel plot (here $8.4 \mathrm{~mm} / 24 \mathrm{~h}$ ). The discharge with a 10 -year return period is then estimated based on the discharge annual maxima (blue dots), available here from 1917 to 2010, using a Gumbel distribution. In this case, the 10-year discharge is $117 \mathrm{~m}^{3} \mathrm{~s}^{-1}$. From this point, referred to as the pivot point, the daily discharge distribution is extrapolated up to a $10000-$ year return period using the GRADEX parameter identified from the rainfall distribution (continuous grey line). The underlying hypothesis is that above this pivot point, which is assumed to correspond to highly saturated catchment conditions, the asymptotic growth of the daily runoff is the same as that for the daily rainfall (i.e. there is no additional storage available in the catchment), producing a parallel behaviour in the rainfall and the discharge distributions. To transform daily discharge into peak discharge, the daily discharge distribution is multiplied by a peak-to-volume coefficient (here 1.04 , shown as a red line).

\section{Comparison of the SCHADEX results with other methods}

\subsection{Estimates for the 1000-year discharge}

The results of the precipitation-runoff modelling methods presented in Sects. 3 and 4, as compared with a statistical flood frequency analysis based on the annual maximum series, are illustrated for the three catchments in Fig. 11. Daily discharge data for the period 1957-2010 were used for the statistical analysis to identify the annual maximum series. This period corresponds to that used to develop the PQRUT and HBV-DF simulations and such a comparison between the precipitation-runoff method and statistical flood frequency analysis is standard practice for design flood analysis in Norway (Midttømme et al., 2011). (For comparison, the annual maximum series for the full period of record can be found in Fig. 9 for each catchment.) The fitted generalised extreme value (GEV) estimates, together with the $90 \%$ confidence interval estimated using bootstrap resampling, are illustrated in Fig. 11. In addition, a two-parameter fitted Gumbel distribution is shown for comparison. Values for the estimated daily averaged discharge corresponding to a 1000-year return period are given for each of the modelling methods, together with the sub-daily instantaneous value for the methods in parentheses. Values for estimates corresponding to 50-, 100-, and 500-year return periods are also plotted for SCHADEX and PQRUT, so that their relative behaviour with increasing return periods is also shown. For PQRUT, these estimates were obtained using precipitation sequences corresponding to 50-, 100- and 500-year return periods. For the 50- and 100 -year return periods, a snowmelt contribution equivalent to $70 \%$ of the value used for the 500- and 1000-year return periods was used for the 50- and 100-year return periods (i.e. from 0.875 to $1.25 \mathrm{~mm} \mathrm{~h}^{-1}$ ). 
Table 2. Comparison of precipitation, snowmelt, catchment saturation conditions and the date of occurrence for the design 1000-year flood values simulated by the three modelling methods, as compared with the conditions associated with the highest observed discharge values for each catchment.

\begin{tabular}{|c|c|c|c|c|}
\hline & PQRUT & HBV-DF & SCHADEX $^{\mathrm{a}}$ & Maximum $Q_{\mathrm{obs}}^{\mathrm{b}}$ \\
\hline \multicolumn{5}{|l|}{ Atnasjø } \\
\hline \multirow{2}{*}{$24 \mathrm{~h}$ precipitation $(\mathrm{mm})$} & 134 & 143 & $85(60-108)$ & 29 \\
\hline & & & $\mathrm{P} 1000=103$ & \\
\hline $72 \mathrm{~h}$ precipitation $(\mathrm{mm})$ & 176 & 188 & $182(126-220)$ & 63 \\
\hline Snowmelt rate $\left(\mathrm{mm} \mathrm{d}^{-1}\right)$ & 30 & 28 & $3(0-22)$ Max $=39$ & 18 \\
\hline Catchment saturation & $100 \%$ & $100 \%$ & $98 \%(81-99 \%)$ & $100 \%$ \\
\hline Date (or season) for Q1000 & JJA & 01/06/2008 & Jun & $01 / 06 / 1995$ \\
\hline \multicolumn{5}{|l|}{ Engeren } \\
\hline \multirow[t]{2}{*}{$24 \mathrm{~h}$ precipitation $(\mathrm{mm})$} & 138 & 119 & $117(97-151)$ & 16 \\
\hline & & & $\mathrm{P} 1000=138$ & \\
\hline $72 \mathrm{~h}$ precipitation $(\mathrm{mm})$ & 176 & 164 & $243(202-282)$ & 44 \\
\hline Snowmelt rate $\left(\mathrm{mm} \mathrm{d}^{-1}\right)$ & 30 & 24 & $0(0-9)$ Max $=35$ & 21 \\
\hline Catchment saturation & $100 \%$ & $100 \%$ & $70 \%(41-93 \%)$ & $100 \%$ \\
\hline Date (or season) for Q1000 & JJA & 29/05/1988 & Sep & $01 / 06 / 1995$ \\
\hline \multicolumn{5}{|l|}{ Krinsvatn } \\
\hline \multirow[t]{2}{*}{$24 \mathrm{~h}$ precipitation $(\mathrm{mm})$} & 197 & 191 & $184(162-213)$ & 156 \\
\hline & & & $\mathrm{P} 1000=202$ & \\
\hline $72 \mathrm{~h}$ precipitation $(\mathrm{mm})$ & 283 & 275 & $368(304-448)$ & 306 \\
\hline Snowmelt rate $\left(\mathrm{mm} \mathrm{d}^{-1}\right)$ & 30 & 31 & $4(0-24) \mathrm{Max}=52$ & 13 \\
\hline Catchment saturation & $100 \%$ & $97 \%$ & $94 \%(58-98 \%)$ & $98 \%$ \\
\hline Date (or season) for Q1000 & DJF & $30 / 10 / 2005$ & Dec & $31 / 01 / 2006$ \\
\hline
\end{tabular}

a Values for the SCHADEX method are given as the median value (modal value for date for Q1000), together with the 10th and 90th percentile values of the range of $10^{4}$ events producing a 1000-year discharge (Figs. 10, 11, and 12). ${ }^{\mathrm{b}}$ Values for snowmelt and catchment saturation conditions for the maximum observed $Q$ are based on calibrated HBV simulations of the event.

Figure 11 indicates notable differences in estimates for the 1000-year discharge derived by the various methods. At Atnasjø, the "traditional" methods, PQRUT, HBV-DF and GRADEX, give much higher estimates than SCHADEX, which lies between the GEV and Gumbel estimates. At Engeren, all modelling methods give higher estimates than statistical flood frequency analysis, particularly SCHADEX and GRADEX. In contrast, at Krinsvatn all of the modelling methods produce estimates which are lower than the GEV estimate based on the annual maximum series. The SCHADEX estimates for Krinsvatn, however, correspond well with the fitted Gumbel distribution for all return periods considered. It should also be noted that PQRUT and HBV-DF, i.e. the methods based on an empirically estimated design precipitation sequence, lie below the $5 \%$ confidence level for the GEV-based estimate for Krinsvatn.

\subsection{Precipitation estimates}

There is a range of factors related to both the precipitation input and the catchment conditions which contribute to the differences between the estimated 1000-year discharge magnitudes. A summary of these factors is given in Table 2 with reference to the PQRUT, HBV-Design Flood and SCHADEX methods, and they are also compared with the observed or simulated values associated with the maximum observed discharge. For PQRUT, the 24 and $72 \mathrm{~h}$ precipitation values correspond directly to the 1000 -year design precipitation sequence, whereas when used in HBV these design values are slightly modified by calibrated HBV model parameters (precipitation correction factor and lapse rate). In contrast, the SCHADEX method generates a range of central (1-day) and 3-day precipitation values which produce 1000-year discharge values under various catchment conditions. The median, 10th and 90th percentile values are given in Table 2, and the full distribution of values is illustrated for the three catchments in Fig. 12. The median values for the SCHADEX central rainfall are somewhat lower than the $24 \mathrm{~h}$ design precipitation estimates for the three catchments. This is anticipated, as the SCHADEX values represent events producing a 1000-year discharge, which may also include a contribution from snowmelt, whereas the precipitation values used as input for PQRUT and HBV-Design Flood correspond to a precipitation sequence with an estimated 1000-year return period, independent of an additional snowmelt contribution or catchment saturation conditions. Similar differences would be expected for the 3-day precipitation values, although this is not the case. The median values for 3-day precipitation generated by SCHADEX are slightly to significantly higher 

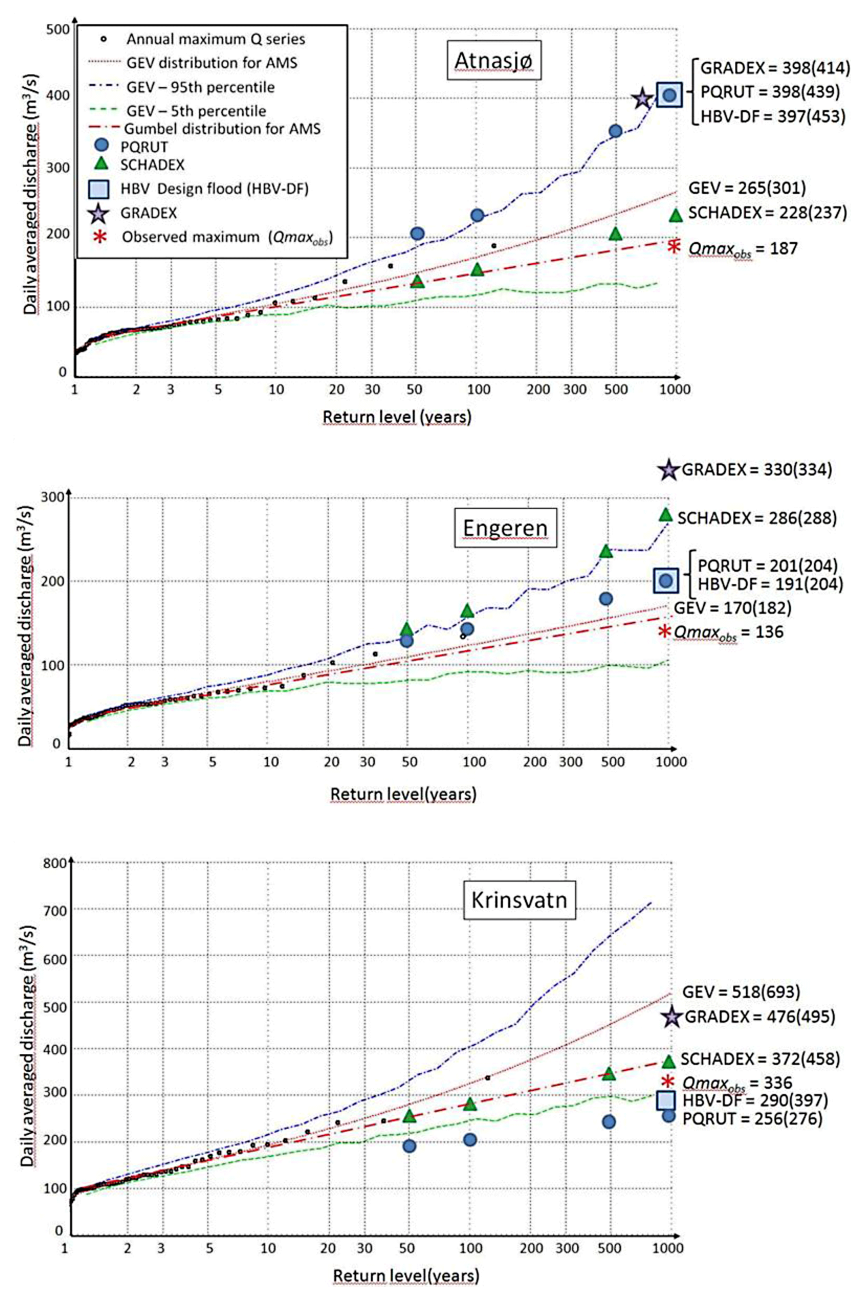

Figure 11. Comparison of estimates for the Q1000 discharges given by the various precipitation-runoff methods with statistical flood frequency analysis based on the annual maximum series.

than those used as input for PQRUT and HBV-Design Flood. At Engeren and Krinsvatn, even the 10th percentile of the distribution of the SCHADEX values is higher than the input precipitation values for PQRUT. It should also be noted that at Krinsvatn, the input $72 \mathrm{~h}$ precipitation for simulating the 1000-year event with PQRUT is less than that estimated as occurring during the period of the highest observed discharge.

\subsection{Snowmelt and catchment saturation conditions}

Snowmelt rates for the PQRUT and HBV-Design Flood methods are very similar, particularly for Atnasjø and Krinsvatn, although these were derived differently. In the case of PQRUT, a value of $30 \mathrm{~mm} \mathrm{~d}^{-1}$ was assumed for all three catchments (see Sect. 4.3), whereas snowmelt is simulated by HBV using a temperature index method. In addition, changes in snow storage are simulated for each of 10 equalarea height zones, such that the value given in Table 2 is
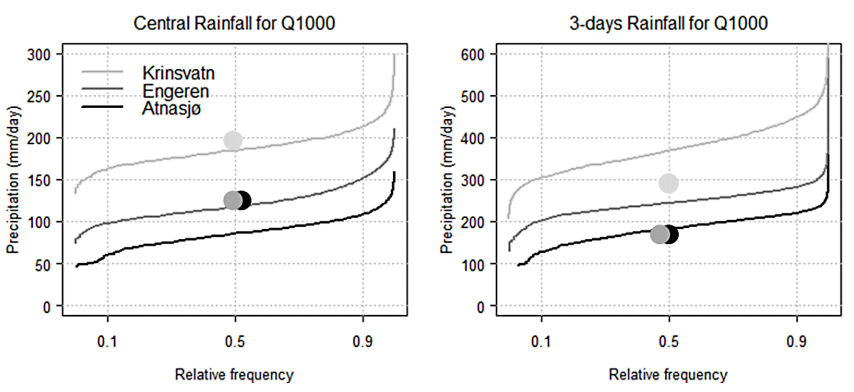

Figure 12. Distributions of central (i.e. 1-day) and 3-day rainfall volumes associated with the $10^{4}$ simulated events producing a 1000-year discharge (Q1000). The values for the design precipitation sequence used in PQRUT are also indicated with solid dots.
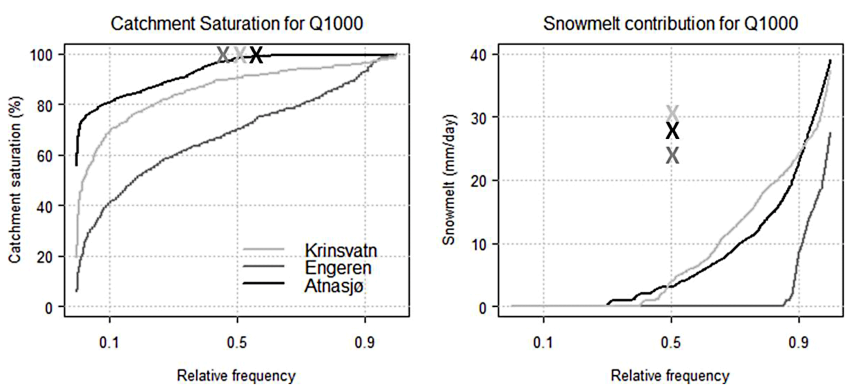

Figure 13. Distributions of catchment saturation conditions and snowmelt rates associated with the $10^{4}$ simulated events producing a 1000-year discharge (Q1000) for the three catchments. The values simulated by HBV-DF for the event with the highest discharge are also indicated with "X".

an average value for the entire catchment. The value given corresponds to the snowmelt rate during the highest simulated discharge in response to the input precipitation sequence. The maxima of all the simulated values are somewhat higher, i.e. 27,33 and $42 \mathrm{~mm} \mathrm{~d}^{-1}$ for Atnasjø, Engeren and Krinsvatn, respectively. The median values of snowmelt for the SCHADEX simulations are significantly lower than those used in PQRUT and simulated by HBV. The full distribution of SCHADEX values for snowmelt associated with discharges with a 1000-year return period is illustrated in Fig. 13. These distributions for Atnasjø and Krinsvatn indicate that the highest $6-7 \%$ of the simulated 1000-year discharges are associated with snowmelt rates similar to or higher than those of the PQRUT and HBV simulations. For Engeren, however, only very few simulations have rates similar to or higher than the $24 \mathrm{~mm} \mathrm{~d}^{-1}$ simulated by HBV.

The distribution of catchment saturation conditions associated with the 1000 year discharge for the SCHADEX simulations is also illustrated in Fig. 13. In contrast with the assumptions underlying the PQRUT application (i.e. that catchment saturation is $100 \%$ ), the SCHADEX results indicate that such discharges can occur over a range of catchment saturation levels, particularly at Engeren. For Atnasjø, the 

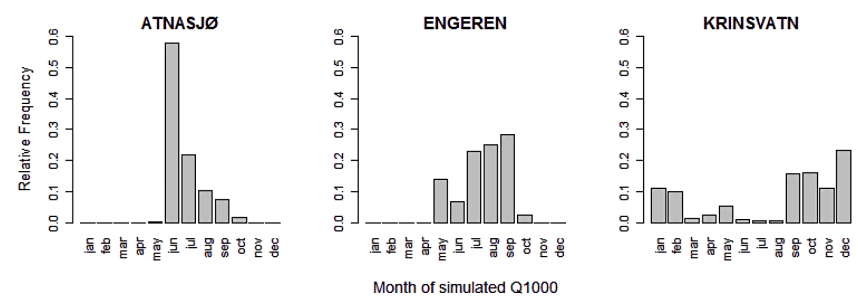

Figure 14. Relative frequency of the $10^{4}$ simulated Q1000 events by month.

median value of the distribution corresponds well with the PQRUT assumptions and the HBV simulations, in that the saturation level is nearly $100 \%$. This is to be expected for a catchment in which peak flows occur primarily during the snowmelt season. For Krinsvatn, the median value is slightly lower, as is also the case for the HBV simulations. For Engeren, however, the median value for the catchment saturation is $70 \%$, indicating a significant potential for catchment losses at the onset of an event for many of the simulations.

\subsection{Seasonality of 1000-year discharge}

The SCHADEX simulations also highlight differences in seasonality with respect to vulnerability to extreme discharges between the catchments. The frequency distributions for the simulated Q1000 by month for the three catchments are shown in Fig. 14. At Atnasjø, the principal months associated with conditions producing 1000-year discharges are June, July and August. This agrees well with the seasonality of annual maximum flows (Fig. 8), the assumed season for extreme events used for the PQRUT estimates (Table 2), the historical date for which the 1000-year precipitation sequence produced the maximum discharge in the HBV-Design Flood simulations, and the date of the observed maximum discharge. The frequency distribution for the SCHADEX simulations at Krinsvatn indicates the autumn and winter months as the periods associated with most of the simulated 1000-year discharges, again in good correspondence with other simulations and observations and reflecting the contrasting flood regime at this location. At Engeren, the SCHADEX simulations suggest July-September as the period most vulnerable to extreme flows, although a notable portion of such flows also occurs in May and June. The annual maximum series, on the other hand, are characterised by a dominance of peak flows in May under observed historical conditions. This is the case for both the entire period of record (1912-2011), and for the shorter period used for the SCHADEX simulations (1970-2008). The annual maxima indicate only one year out of 100 in which the annual maximum occurred outside of the period AprilJune, i.e. on 24 August 1912, and that value has a rank of 57 out of the annual maxima. Differences in the seasonality of the SCHADEX 1000-year discharges relative to that of the observed annual maximum flows point towards a difference in the dominant flood-generating mechanism. The observed annual maximum flows reflect seasonal snowmelt, which ceases in this catchment before the end of June. The SCHADEX simulations suggest that extreme rainfall during summer and autumn periods has the potential to produce the most extreme events in the catchment, independent of a contribution from snowmelt. This is also consistent with the lower values of snowmelt and catchment saturation levels associated with the 1000-year discharges simulated for the catchment (Fig. 13) using the SCHADEX method.

\section{Discussion}

The comparison of results indicates a better agreement between the SCHADEX results and estimates based on statistical flood frequency analysis than between the other methods and statistical analyses at both Atnasjø and Krinsvatn. At Atnasjø, the difference may well be related to the use of a 1000year precipitation sequence to produce a 1000-year discharge with PQRUT and HBV-Design Flood in a catchment which also has a significant contribution from snowmelt. Such an assumption can possibly lead to an overestimation of design flood values in this type of catchment. At Krinsvatn, the particularly low values for the 1000-year discharge generated by the PQRUT and HBV-Design Flood simulations appear to result from $72 \mathrm{~h}$ design precipitation values which are too low, as indicated by a comparison with the observed precipitation during the highest recorded discharge. This underscores the importance of reliable and robust methods for deriving such precipitation values. At Engeren all of the modelling methods produce values which are higher than estimates based on extreme value analysis of the annual maximum series, and the SCHADEX and GRADEX results lie above the 95th confidence level for the fitted GEV distribution for the annual maximum series. A comparison of the precipitation estimates and catchment conditions indicates that the SCHADEX simulations point towards the potential importance of summer and early autumn rainfall events in producing the most extreme events, although the annual flow series is dominated by seasonal snowmelt during the early summer. This would suggest that the asymptotic behaviour of the catchment is driven by extreme precipitation, which is more likely to occur from July to October according to the MEWP distribution, whereas the highest observed flows are consequences of snowmelt. This difference is also supported by the much better fit of the SCHADEX simulations to the over-threshold discharge series, as compared with the annual maximum series illustrated in Fig. 9 for Engeren. In addition, there are other catchments in this region for which some of the highest recorded discharges actually occur during the late summer, although the catchments are otherwise dominated by annual maximum flows in late spring and early summer. This emphasises the benefits of considering all the 
components of flood processes through detailed models (precipitation, snowmelt and precipitation-runoff) to infer the relevant conditions for extreme floods, which can differ from those represented by the highest observed discharges.

The periods used for the SCHADEX simulations, approximately 1972-2010 (full details in Sect. 3.4), are somewhat shorter than those used for statistical flood frequency analysis and the other modelling methods, 1957-2010 (Sect. 5.1), and this could in principle have an impact on the comparison illustrated in Fig. 11. Recent work (Brigode, 2013; Brigode et al., 2014) investigating the sensitivity of various components of the SCHADEX method to hydroclimatological variability indicates that as long as 20-30 years of good quality climatological data are used for developing the precipitation probabilistic model, the SCHADEX results tend to be relatively insensitive to the period considered for developing the rainfall model (i.e. that presented in Figs. 6 and 7 for Atnasjø). This assumes, of course, a degree of stationarity over the entire period of interest, as well as a sufficient number of rainfall events for the analysis. This latter factor was not an issue in the climatic regime considered here, but may become relevant for SCHADEX applications under semi-arid to arid conditions. The period used for hydrological model calibration, in contrast to that used for developing the precipitation probabilistic model, was found by Brigode et al. (2014) to have a relatively large impact on the final SCHADEX estimates.

The comparison of methods indicates several advantages of the SCHADEX approach over the more traditional precipitation-runoff methods for design flood analysis. Of primary interest to the practitioner is the capacity to generate a large range of possible rainfall magnitudes and catchment conditions that can produce an XX-year discharge, rather than requiring the assumption that an XX-year precipitation event produces the corresponding XX-year flood. This should lead to a better correspondence with results of statistical analyses of observed maximum flows, particularly for catchments with large contributions from snowmelt or which have variable levels of saturation at the onset of an extreme precipitation event. The SCHADEX methodology can also highlight potential seasonal flooding hazards not necessarily well represented by the observed annual maximum flow series. In addition, in contrast to continuous simulation methods, the approach is not encumbered by the need to generate an excessively long time series using a weather generator, for example, in order to examine an ensemble of events with return periods of 1000 years and higher.

The further development of a SCHADEX-type methodology for use in regions dominated by extreme events caused by a combination of extreme rainfall and snowmelt requires a more in-depth scrutiny of factors contributing to differences in the snowmelt contributions simulated by the various methods. Some of these differences may reflect differences in the hydrological model structure in that the Nordic version of HBV simulates changes in snow storage for 10 equal area height zones within the catchment, whereas the MORDOR model has a lumped snow model for the entire catchment. Other differences, as discussed above, may reflect actual differences in the seasonality of potential extreme events relative to the annual maximum series, although such a hypothesis can be difficult to verify. The seasonal behaviour, however, could be evaluated further using a more in-depth peak over threshold analyses of observed discharge for this catchment.

For practical applications, a possible disadvantage of the SCHADEX approach relative to the other simulation methods considered here is that it is a somewhat more complex tool and therefore may be more demanding of the user (see Paquet et al. (2013) for a description of the procedure). All three methods considered, i.e. PQRUT, HBV-Design Flood and SCHADEX, require areal estimates for the catchment rainfall as a daily time series. Given these data, the construction of the extreme precipitation sequence for PQRUT and for HBV-Design Flood applications is relatively simple for applications in Norway, relying on the equations given in Førland (1992) and requiring little prior experience. For SCHADEX, the rainfall probabilistic model is built for a given catchment and this entails fitting the MEWP model using a suitable distribution of seasons, setting up a contingency table for the ratios of the centred rainfall to the preceding and subsequent values, as well as building a sub-model for antecedent rainfall. Although tools are available for these analyses within SCHADEX, the practitioner must have sufficient experience to be able to interpret the results and make required adjustments. Both HBV-Design Flood and SCHADEX require hydrological model calibration, and thus are more time-consuming than the simple three-parameter PQRUT model, which can be applied without calibration or calibrated based on observed hydrographs. In addition, both of the long-term simulation methods have longer computer run times, although these are nevertheless minimal as compared with continuous simulation methods.

The current version of SCHADEX requires observed daily discharge data for model calibration and hourly discharge data for assessing the peak-to-volume ratio for use in estimating instantaneous discharge values. Such data are rarely available in catchments for which design flood estimates are required. An advantage of the PQRUT model is that it can also be used in ungauged catchments. Further work to extend the SCHADEX methodology to such catchments would represent a particularly significant advance in methods for design flood analysis.

Acknowledgements. The authors wish to thank A. Efstratiadis and an anonymous reviewer for their constructive comments on an earlier version of the manuscript. The authors gratefully acknowledge support from the COST Action ES0901 FloodFreq which has made the collaboration between NVE and EDF possible, including a Short Term Scientific Mission for Anne Fleig to EDF. In addition, support for this work has been received via internal research funds from NVE in connection with the Klimaendring og 
fremtidige flommer (Climate change and future floods) research project.

Edited by: T. Kjeldsen

Reviewed by: A. Efstratiadis and two anonymous referees

\section{References}

Anderson, T. W.: On the Distribution of the Two-Sample Cramervon Mises Criterion, Ann. Mathemat. Statis., 33, 1148-1159, 1962.

Bárdossy, A., Duckstein, L., and Bogardi, I.: Fuzzy rule-based classification of atmospheric circulation patterns, Int. J. Climatology, 15, 1087-109, 1995

Bergström, S.: Development and application of a conceptual model for Scandinavian catchments, SMHI Report RH07, 1976.

Bergström, S., Harlin, J., and Lindström, G.: Spillway design floods in Sweden: I. New guidelines, Hydrol. Sci. J., 37, 505-519, 1992.

Bergström, S., Hellström, S.-S., Lindström, G., and Wern, L.: Follow-Up of the Swedish Guidelines for Design Flood Determination for Dams, Report No. 1, BE90, Svenska Kraftnät, 2008.

Boé, J. and Terray, L.: A weather type approach to analysing winter precipitation in France: twentieth century trends and influence of anthropogenic forcing, J. Climate, 21, 3118-3133, 2008.

Boughton, W. and Droop, O.: Continuous simulation for design flood estimation - a review, Environ. Modell. Software, 18, 309318, 2003.

Brigode, P.: Changement climatique et risque hydrologique: évaluation de la method SCHADEX en context non-stationnaire. Doctoral dissertation, Université Pierre et Marie Curie - Paris VI, 2013.

Brigode, P., Bernardara, P., Gailhard, J., Garavaglia, F., Ribstein, P., and Merz, R.: Optimization of the geopotential heights information used in a rainfall-based weather patterns classification over Austria, Int. J. Climatol., 33, 1563-1573, 2013.

Brigode, P., Bernardara, P., Paquet, E., Gailhard, J., Garavaglia, F., Merz, R., Mićović, Z., Lawrence, D., and Ribstein, P. Sensitivity analysis of SCHADEX extreme flood estimations to observed hydrometeorological variability, Water Resourc. Res., 50, 353370, 2014.

Cameron, D. S., Beven, K. J., Tawn, J., Blazkova, S., and Naden, P.: Flood frequency estimation by continuous simulation for a gauged upland catchment (with uncertainty), J. Hydrol., 219, 169-187, 1999.

Camici, S., Tarpanelli, A., Brocca, L., Melone, F., and Moramarco, T.: Design soil moisture estimation by comparing continuous and storm-based rainfall-runoff modeling, Water Resourc. Res., 47, WO5527, doi:10.1029/2010WR009298, 2011.

Djerboua, A., Duband, D., and Bois, P.: Estimation des lois des précipitations extrêmes à partir de données journalières completes, La Houille Blanche, 3, 65-74, 2004.

Duband, D. and Garros-Berthet, H.: Design flood determination by the Gradex method, CIGB, ICOLD, 1994.

ECA\&D: European Climate Assessment \& Dataset, http://eca. knmi.nl/ (last access: November 2011), 2011.

Fleig, A.: Scientific Report of the Short Term Scientific Mission - Anne Fleig visiting Électricité de France, Grenoble, 7-16 November 2011 (http://www.cost-floodfreq.eu/component/ k2/item/76-anne-fleig), 2011.
Førland, E.: Manuel for beregning av påregnelige ekstreme nedbørverdier (Manuel for estimating probable extreme precipitation values), DNMI Rapport no. 21/92, 1992.

Gailhard, J.: A bottom-up weather type classification over France: methodology and applications, Geophysical Research Abstracts, 12, EGU2010-10709, EGU General Assembly, 2010.

Garavaglia, F., Gailhard, J., Paquet, E., Lang, M., Garçon, R., and Bernardara, P.: Introducing a rainfall compound distribution model based on weather patterns sub-sampling, Hydrol. Earth Syst. Sci., 14, 951-964, doi:10.5194/hess-14-951-2010, 2010.

Garavaglia, F., Lang, M., Paquet, E., Gailhard, J., Garçon, R., and Renard, B.: Reliability and robustness of rainfall compound distribution model based on weather pattern sub-sampling, Hydrol. Earth Syst. Sci., 15, 519-532, doi:10.5194/hess-15-519-2011, 2011.

Garçon, R.: Prévision opérationnelle des apports de la Durance à Serre-Ponçon à l'aide du modèle MORDOR, Bilan de l'année 1994-1995, La Houille Blanche, 5, 71-76, 1996.

Grimaldi, S., Petroselli, A., Arcangeletti, E., and Nardi, F.: Flood mapping in ungauged basins using continuous hydrologichydraulic modeling, J. Hydrol., 487, 39-47, 2013.

Guillot, P. and Duband, D.: La méthode du gradex pour le calcul de la probabilité des crues à partir des pluies, Publication AIHS, 84, 560-569, 1967.

Kalnay, E., Kanamitsu, M., Kistler, R., Collins, W., Deaven, D., Gandin, L., Iredell, M., Saha, S., White, G., Woollen, J., Zhu, Y., Leetmaa, A., Reynolds, R., Chelliah, M., Ebisuzaki, W., Higgins, W., Janowiak, J., Mo, K. C., Ropelewski, C., Wang, J., Jenne, R., and Joseph, D.: The NCEP/NCAR 40-Year Reanalysis Project, Bull. Am. Meteorol. Soc., 77, 437-471, 1996.

Kuczera, G., Lambert, M., Heneker, T., Jennings, S., Frost, A., and Coombes, P.: Joint probability and design storms at the crossroads, Australian J. Water Resour., 10, 63-79, 2006.

Lawrence, D., Haddeland, I., and Langsholt, E.: Calibration of HBV hydrological models using PEST parameter estimation, NVE Report no. 1-2009, 2009.

Midtøøme, G. H., Pettersson, L. E., Holmqvist, E., Nøtsund, Ø., Hisdal, H., and Sivertsgård, R.: Retningslinjer for flomberegninger (Guidance for flood estimation), NVE Retningslinjer no. 4/2011, 2011.

NERC: Flood Studies Report, Volumes I-V, Natural Environment Research Council, London, 1975.

Obled, C., Bontron, G., and Garçon, R.: Quantitative precipitation forecasts: a statistical adaptation of model outputs though an analogues sorting approach, Atmos. Res., 63, 303-324, 2002.

Paquet, E., Gailhard, J., and Garçon, R., Evolution of the GRADEX method : improvement by atmospheric circulation classification and hydrological modelling, La Houille Blanche, 5, 80-90, 2006.

Paquet, E., Garavaglia, F., Gailhard, J., and Garçon, R., The SCHADEX method: a semi-continuous rainfall-runoff simulation for extreme flood estimation, J. Hydrol., 495, 23-37, 2013.

Pathiraja, S., Westra, S., and Sharma, A.: Why continuous simulation? The role of antecedent moisture in design flood estimation, Water Resour. Res., 48, W06534, doi:10.1029/2011WR010997, 2012.

Plaut, G., Schuepbach, E., and Doctor, M.: Heavy precipitation events over a few Alpine sub-regions and the links with largescale circulation, 1971-1995, Clim. Res., 17, 285-302, 2001. 
Rahman, A., Weinmann, P. E., Hoang, T. M. T., and Laurenson, E. M.: Monte Carlo simulation of flood frequency curves from rainfall, J. Hydrol., 256, 196-210, 2002.

Sælthun, N. R.: The Nordic HBV Model, NVE Publication no. 07, 1996.

Tveito, O. E.: Climatological evaluation of circulation type classifications and precipitation in Norway/Fennoscandia, COST733 Final document, 2011.
Veijalainen, N. and Vehviläinen, B.: The effect of climate change on design floods of high hazard dams in Finland, Hydro. Res., 39, 465-477, 2008.

Wilson, D., Fleig, A. K., Lawrence, D., Hisdal, H., Pettersson, L. E., and Holmqvist, E.: A review of NVE's flood frequency estimation procedures, NVE Report 9-2011, 2011. 